\title{
Ratio of Correct Information Unit and Cognitive Functions in Healthy Elderly Adults
}

\author{
Hyunjoo Choi \\ Department of Communication Disorders, Korea Nazarene University, Cheonan, Korea
}

Correspondence: Hyunjoo Choi, $\mathrm{PhD}$

Department of Communication Disorders, Korea

Nazarene University, 48 Wolbong-ro, Seobuk-gu,

Cheonan 31172, Korea

Tel: $+82-41-570-1677$

Fax: $+82-41-570-7846$

E-mail: hjchoi@kornu.ac.kr

Received: April 7, 2015

Revised: August 11, 2015

Accepted: August 27, 2015

This work was supported by the National Research Foundation of Korea grant funded by the Korean government (NRF-2013S1A5A8023389).

\begin{abstract}
Objectives: The purpose of the present study was to investigate the relationship between the ratio of Correct Information Unit (CIU) and cognitive functions in healthy elderly adults. Methods: Sixty healthy elderly people participated in this study. Discourse samples were collected from conversation and two picture description tasks. The cognitive function tests included attention (Digit Span Test), naming (Korean version of Boston Naming Test [K-BNT]), memory (Seoul Verbal Learning Test) and frontal executive functions (Korean version of Color Word Stroop Test, Korean version of Trail Making Test for elderly [K-TMT-e], Korean version of Controlled Oral Word Association Test [K-COWAT]). Results: The results were as follows. First, there was no significant difference according to gender in the ratio of $\mathrm{CIU}$, but the ratio of $\mathrm{ClU}$ in conversation was significantly higher than that of the picture description task. Second, the ratio of CIU in conversation had no significant correlation to age, educational level or Korean Mini Mental Status Examination (K-MMSE) score, but the ratio of CIU in the picture description had a positive correlation to educational level and the K-MMSE score. Third, the ratio of $\mathrm{CIU}$ in the picture description had significant correlations to performance on the K-BNT, part B of K-TMT-e, and K-COWAT. Fourth, results of regression analysis indicated that performance on the cognitive function tests used this study were significant predictors for the ratio of CIU. Conclusion: These results suggest that the ratio of $\mathrm{CIU}$ is related to performances on naming and frontal executive functions.
\end{abstract}

Keywords: Discourse production, Correct Information Unit, Cognitive function, Healthy elderly
빠르게 진행되는 인구의 고령화와 더불어 최근에는 노화(aging) 로 인한 인지기능의 변화와 관련된 연구가 활발히 진행되고 있다. 노화로 인한 인지기능의 저하는 일반적인 현상으로 이는 뇌 용적 의 변화와 같은 구조적인 문제(Albert \& Knoefel, 2011)와 신경전달 물질 생성 및 혈류분포의 저하와 같은 기능적인 변화에 기인한다 (Hannay, Howieson, Loring, Fischer, \& Lezak, 2004; Park, 2004). 노화로 인한 인지기능의 변화를 살펴본 연구 결과들은 노인의 경 우 주의집중력 손상(Albert, 1994; Madden \& Langley, 2003), 기억 력의 저하(Albert, 1994), 전두엽 집행기능의 저하(Hasher, Zacks, \& May, 1999; Kliegel, Martin, McDaniel, \& Phillips, 2007) 등이 나 타난다고 보고한다. 이러한 노화로 인한 인지기능의 변화는 인지 영역에 따라 그 변화의 정도가 서로 상이하기 때문에 영역별 일반
노인의 인지기능 변화에 대한 연구가 다양하게 이루어지고 있다 (Lee, Kim, Lee, Chung, \& Park, 2012). 노화로 인한 언어 및 의사소 통 능력의 변화 역시 최근 활발히 연구가 진행되고 있으며, 그중에 서도 담화(discourse) 산출과 관련된 연구는 대상자의 실제적인 의 사소통 능력을 통합적으로 반영할 수 있다는 강점 때문에 각광받 는 주제로 알려져 있다(Fleming \& Harris, 2008).

노인의 담화 산출 능력과 관련된 연구는 크게 세 가지 영역으로 나눌 수 있다. 우선 가장 활발히 연구되고 있는 주제는 노화로 인한 담화 산출 능력의 변화와 관련된 것으로 양적인 변화 및 질적인 변 화에 초점이 맞춰져 있다. 우선 담화 산출의 양적인 변화를 살펴보 면 노인이 되어도 산출하는 담화의 물리적인 양은 변화가 없거나 증가하지만 전달하는 적절한 정보량과 주제 전달량은 저하한다 
(Juncos-Rabadán, Pererio, \& Rodríguez, 2005). 다음으로 노화로 인한 담화 산출 능력의 질적인 변화는 양적인 변화보다 두드러지게 나타나는데, 이러한 질적 변화를 구체적으로 살펴보면 첫 번째, 담 화 주제의 일관성 오류를 들 수 있다. 담화 주제의 일관성과 관련된 노화의 영향을 살펴본 연구들은 노인의 경우 담화의 주제에 벗어 난 내용 산출이 증가한다고 보고한다(Burke, 1997; Glosser \& Deser, 1992; Marini, Boewe, Caltagirone, \& Carlomagno, 2005). 이러 한 담화 주제의 일관성 오류는 담화 산출의 조직화(organization) 문제와 관련이 있는데, 이는 노화로 인해 담화안의 정보를 조직하고 요약하는 능력이 저하되어 나타나는 현상이다(Blake, 2006; Gold, Andres, Arbuckle, \& Zieren, 1993; Shadden, 1995). 두 번째 질적인 변화는 담화 내용의 명제적 적절성 저하를 들 수 있다(Kemper, Thompso, \& Marquis, 2001; Marini et al., 2005). 이는 담화 산출 내용의 부적절성과 더불어 부정확한 정보 전달, 개인적인 정보의 개입 등 정보 전달의 불명료성과 관련이 있다(Blake, 2006). 세 번째 질적인 변화는 구문 능력의 변화(Marini et al., 2005)를 들 수 있는 데, 노인의 경우 담화산출 시 사용하는 구문의 복잡성에 제한을 보 인다(Kemper et al., 2001). 마지막 질적인 변화로는 담화 산출 시 의 미착어(semantic paraphasia), 착문법증(paragrammatism) 등 구 어 산출 오류의 증가를 들 수 있다(Kemper et al., 2001). 이렇듯 노 인의 주제에 벗어난 담화 산출 및 정보 전달 능력의 저하를 비롯한 다양한 질적인 변화들은 대화파트너와의 의사소통 문제를 야기시 켜 타인과의 사회적 상호작용을 방해하는 결과를 초래한다(Pushkar et al., 2000). 이러한 노화로 인한 담화 산출 능력의 변화는 70대 에서 가장 가파른 변화 양상을 보이며(Kemper et al., 2001), 80대 이 후에는 변화 속도가 둔화되는 것으로 알려져 있다(Ulatowska, Chapman, Highley, \& Prince, 1998).

현재까지 노인의 담화 산출 능력을 평가하기 위하여 많은 담화 산출 분석 변인들이 개발되어 왔다. 그중에서도 특히 담화 안의 적 절한 정보 전달 능력을 평가하기 위한 의미적(semantic) 측면의 분 석 변인들이 다양하게 사용되었다(Brookshire, 2007). Yorkston과 Beukelman (1980)은 표준화된 그림설명 과제를 통한 담화의 '내용 단위(content unit)' 분석을 시도하여, '내용 단위 수'와 '분당 내용 단위 수로 담화를 분석하였다. 또한, Nicholas와 Brookshire (1995) 는 해당 자극에서 가장 중요한 정보를 전달하는 능력인 '주요 개념 (main concepts)' 분석법을 사용하여 대상자의 정보 전달 능력의 적절성을 평가하였다. 그러나 이러한 분석은 정상인들의 발화를 분석하여 과제에 적합한 내용단위 및 주요개념을 정의하고 평가하 기 때문에 정해진 그림설명 과제에 국한된 분석만 가능하다는 제한 점이 있다. 이러한 제한점을 보완하기 위해 개발된 담화 분석 변인
이 'Correct Information Unit (CIU)'이다. CIU는 '문맥상 명료하 고, 주제나 과제에 적합한 정보를 제공하는 단어'로 정의되며(Brookshire \& Nicholas, 1994; Kwon, Kim, Choi, Na, \& Lee, 1998; Nicholas \& Brookshire, 1993), 객관적인 변인으로 정보 전달력을 평가할 수 있으며 과제의 제한없이 사용할 수 있다는 장점이 있다(Kwon et al., 1998). CIU 분석의 구체적인 변인으로는 ‘총 CIU 수’ '분당 CIU 수, 'CIU 비율' 등이 사용된다. 특히 '담화 산출의 전체 단어에서 $\mathrm{CIU}$ 가 차지하는 비율'로 정의되는 $\mathrm{CIU}$ 비율은 정보 전달의 적절 성 및 효율성을 평가하는 유용한 지표로 알려져 있다(Brookshire, 2007; Kwon et al., 1998).

노인의 담화 산출 능력에 관한 다음 연구 주제는 성별, 교육 정도 및 선별적 인지기능과 같은 개인 관련 변수가 담화 산출 능력에 미 치는 영향에 관련된 것이다. 이러한 연구들의 결과를 종합하면 담 화 산출 능력, 특히 적절한 정보를 전달하는 능력에 있어서는 성별 에 의한 차이가 없는 것으로 알려져 있으며, 교육 정도 및 선별적인 인지기능에 의해 영향을 받는 것으로 알려져 있다(Ardila \& Rosselli, 1996; Cheon, 2011; Kwon et al., 1998; Mackenzie, 1999). 즉, 교 육 수준이 높고, 선별적인 수준에서의 인지기능이 높은 경우 효율 적으로 적절한 정보를 전달하는 능력이 뛰어남을 알 수 있다.

마지막 노인의 담화 산출 능력과 관련된 연구 주제는 담화를 유 도하기 위한 과제에 따른 담화 산출 능력의 차이에 관한 것이다. 대 상자의 담화를 수집하기 위해 다양한 과제들이 사용되지만 그중 가장 많이 사용되는 과제는 그림설명 과제이다(Ardila \& Rosselli, 1996; Cooper, 1990). 그러나 담화 과제는 과제의 특징, 과제제시 양 식, 인지적 요구 정도에 따라 서로 다른 영향을 받는다(Cheon, 2011). 예를 들어, 대화 과제의 경우 가장 덜 구조화되고 담화 산출 상황이 자연스러워 사전 계획을 요구하지 않고, 형식에 구애 받지 않는다 (Lee \& Kim, 2001; Nippold, Hesketh, Duthie, \& Mansfield, 2005). 그에 반해 주어진 그림을 보고 설명해야 하는 그림설명 과제는 대 화에 비해 구조화되어 있으며, 그림에 대한 이해와 함께 참조물에 대한 설명 능력을 요구하기 때문에 인지적으로 더 많은 부담을 가 지게 된다(Bracy \& Drummond, 1993; Cheon, 2011; Choi, 2007). 이와 같은 차이로 인해 사용된 담화 과제에 따라 수행 차이가 나타 날수 있으므로 대상자의 실제적인 담화 능력을 평가하기 위해서는 두 가지 이상의 과제를 사용하는 것이 권고되고 있다(Shadden, Burnette, Eikenberry, \& DiBrezzo, 1991).

지금까지의 연구에 따르면 담화 산출 능력은 의미, 구문, 화용적 인 측면의 언어 능력 자체뿐 아니라 주의집중력, 기억력, 전두엽 집행 기능 등 다양한 인지기능과 밀접한 관련이 있다(Hinchliffe, Murdoch, Chenery, Baglioni, \& Harding-Clark, 1998). 실제로 의사소 
통 상황에서 문맥을 적절히 유지하고, 적절한 정보를 취합하여 목 표에 맞는 반응을 산출하는 능력은 인지적 자원을 효율적으로 사 용하는 능력과 밀접하게 관련이 있다(Braver, 2005; Foos, 1995). 특 히, 뇌손상 환자의 경우 담화 산출 능력과 인지기능 손상이 밀접한 관련이 있는 것으로 알려져 있다(Mar, 2004). 이와 관련된 연구 결 과에 따르면, 담화 산출 능력은 외상성 뇌손상 환자의 경우 전두엽 집행기능과 유의한 상관이 있는 것으로 나타났으며(Coelho, 2002; Tucker \& Hanlon, 1998), 경도인지장애(mild cognitive impairment) 환자의 경우에는 작업기억과 관련이 있는 것으로 나타났다(Caspari \& Parkinson, 2000). 그러나 일반 노인의 담화 산출 능력 및 인지 기능에 관한 연구는 각각의 기능에 대해 단편적으로 이루어졌을 뿐 실제적인 담화 산출 능력과 인지기능 사이의 관련성에 관한 연 구는 거의 없는 실정이다. 따라서 본 연구는 CIU 분석을 통해 일반 노인의 정보 전달 능력을 대화와 그림설명 과제를 사용하여 평가하 고, 이러한 담화 산출 능력과 인지기능과의 관련성을 알아보는 것 을 목적으로 하였다. 구체적인 연구문제는 다음과 같다. 첫째, 성별 과 담화 과제에 따른 CIU 비율의 차이를 알아본다. 둘째, 담화 과제 에 따른 CIU 비율과 연령, 교육 정도, 한국판간이정신상태검사(Korean Mini-Mental State Examination, K-MMSE; Kang, 2006) 점 수와 같은 개인 요인의 상관을 알아본다. 셋째, 담화 과제에 따른 $\mathrm{CIU}$ 비율과 이름대기 능력, 주의집중력, 기억력, 전두엽 집행기능 등의 다양한 인지기능 평가 결과와의 상관을 알아본다. 넷째, 인지 기능 검사 결과가 담화산출 능력에 미치는 영향을 알아본다.

\section{연구 방법}

\section{연구 대상}

본 연구에서는 65-85세의 일반 노인 60명(남성 30명, 여성 30명) 을 대상으로 하였다. 일반 노인의 선정기준은 다음과 같다. (1) 한국 판 간이정신상태검사(Korean Mini-Mental State Examination, KMMSE; Kang, 2006) 점수가 연령과 교육년수 규준의 -1 표준편차 (16\%ile) 이상의 정상 범주에 속하고, (2) 본인 혹은 가족의 보고에 의해 인지기능에 영향을 줄 수 있는 신경학적, 정신과적 질환의 병 력이 없고, (3) 과제 수행을 위한 시각 및 청각 능력을 보유하고 있어 야 한다. 연구 대상자의 성별에 따른 연령, 교육 정도 및 K-MMSE 결과를 Table 1에 제시하였다. 또한, 연구 대상자의 성별에 따라 연 령, 교육 정도 및 K-MMSE 점수의 차이가 유의한지 알아보기 위하 여 독립표본 $t$-검정을 실시하였다. 그 결과, 연령과 K-MMSE 점수 는 성별에 따라 유의한 차이가 나타나지 않았지만, 교육 정도는 남 성이 여성에 비해 유의하게 높았다 $(t=2.761, p<.05)$.
Table 1. Results for age, education level and K-MMSE score by gender

\begin{tabular}{lcrr}
\hline & Male & \multicolumn{1}{c}{ Female } & \multicolumn{1}{c}{ Total } \\
\hline Age (yr) & $75.10(6.06)$ & $73.97(5.76)$ & $74.53(5.90)$ \\
Education (yr) & $11.37(4.12)$ & $8.10(5.00)$ & $9.73(4.83)$ \\
K-MMSE & $26.56(1.72)$ & $26.97(1.56)$ & $26.76(1.64)$ \\
\hline
\end{tabular}

Values are presented as mean (SD).

K-MMSE = Korean Mini Mental Status Examination (Kang, 2006).

\section{연구 과제}

담화 산출 과제

본 연구에서는 대상자에게 담화를 유도하기 위한 과제로 대화와 그림설명 과제를 사용하였다. 우선 대화 과제는 일상적인 대화 상 황에서의 담화 산출 능력을 평가하는 과제로 자연스러운 분위기에 서 질문을 통하여 대화를 유도하였다. 대화 과제의 질문은 기존의 연구(Lee \& Kim, 2001)에 따라 한국판 웨스턴 실어증 검사(Korean version of the Western Aphasia Battery, K-WAB; Kim \& Na, 2001) 의 ‘스스로 말하기' 항목의 질문들을 사용하였다. 대화 상황에서 대상자가 질문에 대답하기를 어려워하는 경우 해당 질문 내용을 유도하기 위한 하위 질문들을 추가적으로 제시하였다. 다음으로 그림설명 과제는 주어진 그림을 보고 그 내용을 설명하는 과제로 사용이 간단하고 분석이 용이하여 가장 널리 사용되는 담화 산출 과제이다(Duong, Tardif, \& Ska, 2003). 다만, 사용하는 그림의 내 용 및 복잡성에 따라 담화 산출 능력에 차이가 나타나며, 특히 한 장으로 구성된 단일그림 과제와 여러 장으로 구성된 연속그림 과제 간의 차이가 있을 수 있다(Marini et al., 2005). 따라서 본 연구에서 는 단일그림과 연속그림을 모두 사용하였다. 본 연구에서는 단일그 림으로 Boston Cookie-Theft picture (Goodglass \& Kaplan, 1983) 를, 연속그림으로 부부싸움 그림(Nicholas \& Brookshire, 1993)을 사용하였다. 사용한 그림들은 일반 성인 및 실어증 환자를 대상으 로 한 국내 연구에서 이해에 어려움이 없고 문화적인 차이도 나타 나지 않는 것으로 알려져 있다(Im, Kwon, \& Sim, 2001). 그림설명 과제에서는 대상자에게 그림을 제시하고 "이 그림을 잘 보시고 그림 에서 일어나고 있는 일을 말씀해주세요”라고 지시하였다. 대상자 의 반응은 녹음한 후 즉시 전사하였다. 30 초 이상의 담화만을 분석 대상으로 하였으며, 기존의 연구를 바탕으로 담화 산출의 효율성 과 정보 전달 능력을 평가하는 것으로 알려진 CIU 비율을 분석 변 인으로 하였다(Choi, 2013; Im et al., 2001; Kwon et al., 1998). CIU 란 '주제에 적합하고 정확한 정보를 제공하는 단어'로 정의하였으 며, CIU 비율은 담화 산출의 총 단어 중 CIU 가 차지하는 비율로 평가하였다(Kwon et al., 1998; Nicholas \& Brookshire, 1993). CIU 를 판단하는 기준은 대화와 그림설명 과제를 사용한 기존의 연구 
와 같이 그림설명 과제에서는 제시된 그림에서 나타난 적절한 정보 로 판단된 경우, 대화 과제에서는 질문에 적합한 내용의 대답으로 판단된 경우로 하였다(Choi, 2007; Cheon, 2011; Koo \& Choi, 2015). $\mathrm{CIU}$ 의 단위는 내용어 산출을 통한 의미적인 측면을 고려하며 어절 단위로 하였다(Choi, 2013; Im et al., 2001).

\section{인지기능 검사}

\section{선별적 인지기능}

대상자의 선별적인 인지기능을 평가하기 위하여 한국판 간이정 신상태검사(Korean Mini-Mental State Examination, K-MMSE; Kang, 2006)를 사용하였다. MMSE는 가장 널리 사용되는 인지기 능 선별검사로 지남력, 저장 및 재생능력을 포함한 단기기억력, 주의 집중력 및 언어 능력 등 다양한 인지적 요소가 포함되어 있다(Ravetti, Rosso, Berretta, \& Moscato, 2010).

\section{주의집중력}

대상자의 주의집중력(attention)을 평가하기 위하여 숫자 외우기 검사(Digit Span Test; Kang, Chin, \& Na, 2002)를 사용하였다. 숫 자 외우기 검사는 주의집중력과 작업기억을 평가하는 검사로 본 연 구에서 사용된 숫자 외우기 검사는 숫자 바로 외우기(forward digit span)와 숫자 거꾸로 외우기(backward digit span)로 구성되어 있 다. 숫자 바로 외우기 검사는 3-9개의 숫자를 1초에 숫자 하나 정도 의 속도로 불러주고 외운 숫자의 개수를 점수로 한다(9점 만점). 숫 자 거꾸로 외우기 검사는 숫자 바로 외우기 검사와 유사한 방법으 로 진행하되 2-8개까지 불러준 숫자를 역순으로 외우게 하는 검사 이다(8점 만점).

\section{이름대기 능력}

대상자의 대면 이름대기(confrontation naming) 능력을 평가하기 위하여 한국판 보스톤 이름대기 검사의 병렬 단축형(Kang, Kim, $\& \mathrm{Na}, 2000)$ 중 A형(15문항 60 점 만점)을 사용하였다. 본 검사는 주 의집중력에 제한을 보이는 고령의 환자에게 사용하기 편리하면서 도 한국판 보스톤 이름대기 검사(Korean version of Boston Naming Test, K-BNT; Kim \& Na, 1997)와 동등한 효율성을 지닌 것으 로 알려져 있다(Kang et al., 2000).

기억력

대상자의 기억력을 평가하기 위하여 서울언어학습검사(Seoul Verbal Learning Test, SVLT; Kang \& Na, 2003)를 사용하였다. 본 검사는 총 12 개의 단어로 구성되어 있으며 단어를 불러준 후 기억
나는 단어를 즉각적으로 말하도록 하는 즉각회상(immediate recalls)(3차 시행 총 36 점), 즉각회상 과제 수행 약 20 분 경과 후 기억 나는 단어를 말하도록 하는 지연회상(delayed recalls)(12점), 단어 를 불러준 후 해당 단어가 검사 단어에 포함되어 있었는지 없었는 지를 판단하는 재인(recognition)(정반응 점수 12점, 정부정 점수 12점, 총 24점)의 세 가지 하위 항목으로 구성되어 있다.

\section{전두엽 집행기능}

대상자의 전두엽 집행기능(frontal executive function)을 평가하 기 위하여 스트룹 테스트(Stroop test), 기호 잇기 검사-(trail making test), 통제 단어 연상 검사(controlled oral word association test)를 실시하였다.

스트룹 테스트: 스트룹 테스트는 전두엽 집행기능 중 억제(inhibition) 기능을 주로 평가하는 과제로 알려져 있으며, 본 연구에서 는 Korean-Color Word Stroop Test (K-CWST; Lee, Kang, \& Na 2000)를 사용하였다. 본 검사는 글자와 글자의 색깔이 일치하지 않 는 2장의 카드로 글자읽기 조건과 색깔읽기 조건의 각 조건당 112 개의 자극으로 구성되어 있다. 대상자는 제한 시간 2 분 동안 각 조 건에 따라 글자와 색깔을 말해야 하며, 정반응 수와 반응시간을 기 록한다. K-CWST는 단어읽기 조건의 정반응 수와 정반응 항목당 반응시간(초), 색깔읽기 조건의 정반응 수와 정반응 항목당 반응시 간, 단어읽기 조건과 색깔읽기 조건 간의 간섭점수(inference score) 를 측정지표로 한다.

기호 잇기 검사: 기호 잇기 검사는 전두엽 집행 기능 중 계획 및 과제 전환 능력 등을 평가하는 과제로 알려져 있으며, 본 연구에서는 한국판 노인형 기호 잇기 검사(Korean version of Trail Making Test for elderly, K-TMT-e; Lee, 2006)를 사용하였다. 본 검사는 1-15까지의 숫자를 순서대로 연결하는 Part A와 1-8의 숫자와 월-일의 요일을 순 서대로 번갈아 가면서 연결하는 Part B로 구성되어 있다. K-TMT-e 는 Part A와 Part B의 각 수행시간(초) 및 오류수를 측정지표로 한다.

통제 단어 연상 검사: 통제 단어 연상 검사는 전두엽 집행기능 중 구어 유창성(verbal fluency)을 평가하는 과제로 알려져 있으며, 본 연구에서는 Kang, Chin, Na, Lee와 Park (2000)에 의해서 표준 화된 한국판 통제 단어 연상 검사(Korean version of Controlled Oral Word Association Test, K-COWAT)를 사용하였다. 본 검사 는 1 분 동안에 주어진 범주에 해당하는 단어를 말하도록 하는 검 사로 '동물'과 '가게물건'의 의미 유창성(semantic fluency)과 ' ᄀ', 'O', '스으로 시작되는 단어를 말하는 음소 유창성(phonemic fluency) 검사로 구성되어 있다. 본 연구에서는 의미 유창성 점수의 합 과 음소 유창성 점수의 합을 K-COWAT의 측정지표로 하였다. 


\section{연구절차}

본 검사는 조용한 장소에서 개별적으로 실시하였다. 담화 산출 과제는 대상자가 과제를 이해하고 있다고 여겨진 후에 실시하였으 며, 인지기능 평가 과제는 표준화된 검사 절차에 따라 실시하였다. 실험절차에서 대상자가 즉각적으로 반응을 하지 못하는 경우 각 과제에 따른 단서 제공 방법에 따라 단서를 제시하였다. 대상자의 모든 반응은 EDIROL R-09 WAVE/MP3 Recorder를 사용하여 녹 음하고 즉시 전사하였다. CIU 비율 분석의 신뢰도를 평가하기 위 해 수집된 모든 자료를 대상으로 제 2 평가자와의 평가자 간 신뢰도 (interjudge reliability)를 측정하였으며, 대화와 그림설명 과제 모두 에서 $95 \%$ 이상의 평가자 간 일치율을 보였다.

\section{통계분석}

모든 통계분석은 PASW 18.0 프로그램을 사용하였다. 우선, 성 별과 담화 과제에 따른 차이를 알아보기 위하여 교육 정도를 공분 산으로 처리하여 혼합분산분석을 실시하였다. 다음으로 담화 과제 에 따른 CIU 비율과 연령, 교육 정도, K-MMSE 점수의 상관을 알 아보기 위하여 상관분석을 실시하였다. 또한, 인지기능 평가 결과 와 담화 과제에 따른 $\mathrm{CIU}$ 비율의 상관분석을 실시한 후 이러한 인 지기능 검사 결과가 담화 산출 능력에 미치는 영향을 알아보기 중 다회귀분석을 실시하였다.

\section{연구 결과}

\section{성별과 담화 과제에 따른 $\mathrm{CIU}$ 비율의 차이}

성별과 대화, 그림설명의 담화 과제에 따른 CIU 비율을 Figure 1 에 제시하였다. 우선, 성별과 담화 과제에 따른 CIU 비율의 차이를

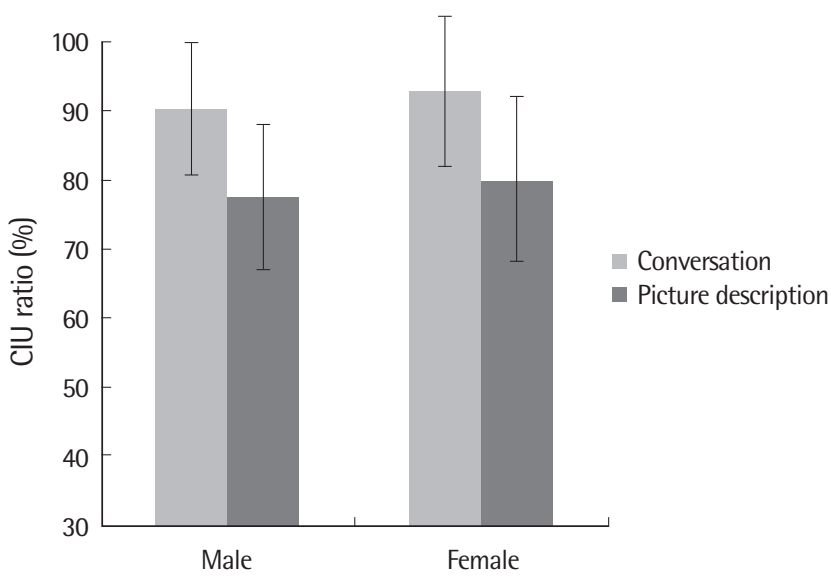

Figure 1. Ratio of Correct Information Unit (CIU) by gender and task.
알아보기 위하여 교육 정도를 공분산으로 처리하여 혼합분산분석 을 실시하였다. 그 결과 성별에 의한 차이는 유의하지 않았으나 $(F=$ $2.841, p>.05)$, 과제에 의한 차이는 그림설명 과제에 비해 대화 과제 에서의 CIU 비율이 유의하게 높은 것으로 나타났다 $(F=41.509$, $p<.001)$. 성별과 과제에 의한 상호작용 효과는 유의하지 않았다 $(F=1.345, p>.05)$.

\section{담화 과제에 따른 CIU 비율과 연령, 교육 정도, K-MMSE 점수의 상관}

다음으로 담화 과제에 따른 CIU 비율과 연령, 교육 정도, K-MMSE 점수의 상관을 알아보기 위하여 상관분석을 실시하고 그 결과를 Table 2에 제시하였다. 결과를 살펴보면 대화 과제의 CIU 비율은 연령, 교육 정도, K-MMSE 점수와 유의한 상관이 없는 것으로 나타 났다. 그러나, 그림설명 과제의 CIU 비율은 연령과는 유의한 상관 이 없었으나, 교육 정도 및 K-MMSE 점수와는 정적상관이 있는 것 으로 나타났다.

\section{담화 과제에 따른 CIU 비율과 인지기능 간의 상관}

담화 과제에 따른 인지기능 평가 결과의 기술통계치를 Table 3에 제시하였다. 또한, 각 인지기능 평가 결과와 담화 과제에 따른 CIU 비율의 상관분석을 실시하고 그 결과를 Table 4 에 제시하였다. 상 관분석 결과 대화 과제에서의 $\mathrm{CIU}$ 비율은 모든 인지기능 영역의 과제 수행력과 유의한 상관이 나타나지 않았다. 그러나, 그림설명 과제에서의 $\mathrm{CIU}$ 비율은 K-BNT 점수, K-COWAT의 의미, 음운 유 창성 점수합과는 정적상관을 보였으며, K-TMT-e의 Part B의 수행 시간 및 오류 수와는 부적상관을 보였다.

\section{그림설명 과제의 CIU 비율에 인지기능이 미치는 영향}

마지막으로 그림설명 과제에서의 CIU 비율에 인지기능이 미치 는 영향을 알아보기 위하여 교육년수 및 K-MMSE 점수, 이름대기, 주의집중력, 기억력, 전두엽 집행기능의 수행력을 독립변수로 하고 그림설명 과제의 CIU 비율을 종속변수로 입력(Enter) 방법을 이용 한 중다회귀분석을 실시하였다. 그 결과, 교육년수와 K-MMSE 점

Table 2. The correlation coefficients among age, education, K-MMSE score and ratio of CIU by task

\begin{tabular}{lccc}
\hline Task & Age & Education & K-MMSE \\
\hline Conversation & .200 & .127 & .159 \\
Picture description & .018 & $.329^{*}$ & $.257^{*}$
\end{tabular}

K-MMSE $=$ Korean Mini Mental Status Examination (Kang, 2006); CIU=Correct Information Unit.

${ }^{*} p<.05$. 
Table 3. Descriptive statistics for performances on the neuropsychological test

\begin{tabular}{llc}
\hline & \multicolumn{1}{c}{ Task } & Mean (SD) \\
\hline Attention & Forward digit span & $5.83(1.62)$ \\
& Backward digit span & $3.62(1.26)$ \\
Naming & K-BNT & $45.67(7.67)$ \\
Memory & SVLT immediate recall & $16.72(5.74)$ \\
& SVLT delayed recall & $4.5(2.83)$ \\
& Recognition score & $19.25(2.49)$ \\
Frontal & K-CWST & \\
executive & Word reading: number of correct responses & $107.05(8.41)$ \\
function & Word reading: reaction time & $.89(.26)$ \\
& Color reading: number of correct responses & $71.80(21.80)$ \\
& Color reading: reaction time & $1.68(.47)$ \\
& Inference score & $.82(.56)$ \\
& K-COWAT & \\
& Semantics fluency & $30.63(6.81)$ \\
& Phonemics fluency & $21.15(10.78)$ \\
& K-TMT-e & \\
& Part A: reaction time & $35.07(15.96)$ \\
& Part A: number of errors & $.07(.25)$ \\
& Part B: reaction time & $77.13(45.72)$ \\
& Part B: number of errors & $1.38(2.23)$ \\
\hline
\end{tabular}

K-BNT = Korean version of Boston Naming Test (Kim \& Na, 1997); SVLT=Seoul Verbal Learning Test (Kang \& Na, 2003); K-CWST=Korean version of Color Word Stroop Test (Lee, Kang, \& Na 2000); K-COWAT=Korean version of Controlled Oral Word Association Test (Kang, Chin, Na, Lee, \& Park, 2000); K-TMT-e=Korean version of Trail Making Test for elderly (Lee, 2006).

수, 인지기능 검사의 수행력을 포함한 회귀모형은 유의하게 나타났 으며 $(F=2.557, p<.01), \mathrm{CIU}$ 비율을 예측하는 설명량은 약 $54.8 \%$ 였다. 유의확률은 K-BNT 점수, 숫자 거꾸로 외우기 점수, K-TMT-e Part A의 수행시간과 Part B의 오류 수가 . 05 수준에서 통계적으로 유의한 것으로 나타났다.

\section{논의 및 결론}

본 연구에서는 일반 노인의 정보 전달 능력을 대화와 그림설명 과제를 사용하여 평가하고, 이러한 정보 전달 능력과 이름대기, 주 의집중력, 기억력, 전두엽 집행기능 등의 인지기능의 상관을 살펴보 았다. 결과를 구체적으로 살펴보면 다음과 같다.

첫째, 성별과 담화 과제에 따른 차이에서 성별에 의한 차이는 유 의하지 않았으나 과제에 의한 차이는 그림설명 과제에 비해 대화 과 제의 CIU 비율이 유의하게 높은 것으로 나타났다. 우선, 이러한 결 과는 담화 산출 능력 중 적절한 정보를 전달하는 능력에 있어서는 성별에 의한 차이가 나타나지 않는다고 보고한 기존의 연구 결과와 일치한다(Ardila \& Rosselli, 1996; Cheon, 2011; Choi, 2012; Kwon et al., 1998). 다음으로 대화와 그림설명 과제에 의한 차이는 일반 노 인의 경우 구조화되어 있는 그림설명 과제에 비해 대화와 같은 자
Table 4. Correlation among the ratio of Correct Information Unit by task and performances on the neuropsychological task

\begin{tabular}{|c|c|c|c|}
\hline & \multirow{2}{*}{ Task } & \multicolumn{2}{|c|}{$\begin{array}{c}\text { Pearson's correlation } \\
\text { coefficient }\end{array}$} \\
\hline & & $\begin{array}{l}\text { Conversa- } \\
\text { tion }\end{array}$ & $\begin{array}{l}\text { Picture de- } \\
\text { scription }\end{array}$ \\
\hline \multirow[t]{2}{*}{ Attention } & Forward digit span & .133 & .155 \\
\hline & Backward digit span & .002 & .087 \\
\hline Naming & K-BNT & .197 & $.498^{*}$ \\
\hline \multirow[t]{3}{*}{ Memory } & SVLT immediate recall & .085 & .183 \\
\hline & SVLT delayed recall & .064 & .206 \\
\hline & Recognition score & .040 & .195 \\
\hline \multirow{14}{*}{$\begin{array}{l}\text { Frontal } \\
\text { executive } \\
\text { function }\end{array}$} & K-CWST & & \\
\hline & Word reading: number of correct responses & .082 & .022 \\
\hline & Word reading: reaction time & -.078 & -.053 \\
\hline & Color reading: number of correct responses & .049 & .180 \\
\hline & Color reading: reaction time & -.024 & -.179 \\
\hline & Inference score & -.025 & -.057 \\
\hline & K-COWAT & & \\
\hline & Semantics fluency & .151 & $.258^{*}$ \\
\hline & Phonemics fluency & .008 & $.258^{*}$ \\
\hline & K-TMT-e & & \\
\hline & Part A: reaction time & -.093 & -.096 \\
\hline & Part A: number of errors & -.096 & -.099 \\
\hline & Part B: reaction time & -.113 & $-.313^{*}$ \\
\hline & Part B: number of errors & -.158 & $-.373^{*}$ \\
\hline
\end{tabular}

K-BNT = Korean version of Boston Naming Test (Kim \& Na, 1997); SVLT = Seoul Verbal Learning Test (Kang \& Na, 2003); K-CWST=Korean version of Color Word Stroop Test (Lee, Kang, \& Na 2000); K-COWAT = Korean version of Controlled Oral Word Association Test (Kang, Chin, Na, Lee, \& Park, 2000); K-TMT-e=Korean version of Trail Making Test for elderly (Lee, 2006).

${ }^{*} p<.05$.

연스럽고 편안한 상황에서 더 적절하고 효율적으로 정보를 전달하 고 있음을 알 수 있다. 이러한 대화와 그림설명 과제 사이의 유의한 차이를 보고한 연구들은 정상적인 인지기능을 가진 노인들을 대상 으로 한 연구(Cheon, 2011; Choi, 2007) 및 실어증 환자들을 대상으 로 한 연구에서 공통적인 결과를 보고하고 있다(Deloche, Jean-Louis, \& Seron, 1979; Koo \& Choi, 2015). 이러한 과제의 차이는 노화로 인한 이름대기 문제와도 연결시켜 생각해 볼 수 있다. 즉, 대화 과제 에서는 설명하고자 하는 적절한 어휘 찾기(word finding)에 실패할 경우 의미적으로 유사한 다른 어휘로 바꿔 표현하는 것이 어느 정 도 자유롭지만, 그림설명의 경우 정확한 참조물에 해당되는 어휘 인출에 실패했을 때 적절한 정보를 전달하는 것에 실패할 가능성 이 높아진다(Koo \& Choi, 2015). 따라서 노화로 인한 어휘 인출(lexical retrieval) 능력의 저하로 인한 영향이 그림설명 과제에서 더 두 드러지게 나타난다고 생각할 수 있다. 그러나 이러한 차이는 과제 에 따라 CIU의 판단 기준이 다르기 때문에 나타날 가능성 또한 배 제할 수 없다. 즉, 그림설명 과제의 경우 제시된 그림의 내용을 정확 하게 산출하였는지 연구자가 판단 가능하여 CIU 판단이 비교적 
명확한 반면, 대화 과제에서는 질문에 적합하다고 판단되는 반응 이라면 사실 여부와 관계없이 CIU로 간주되기 때문에 CIU 비율이 다소 높아질 가능성 또한 반드시 고려해야한다(Koo \& Choi, 2015).

둘째, 담화 과제에 따른 CIU 비율과 연령, 교육 정도, K-MMSE 점수의 상관분석 결과 대화 과제의 $\mathrm{CIU}$ 비율은 어떠한 변인과도 유의한 상관이 없는 것으로 나타났지만, 그림설명 과제의 CIU 비 율은 연령과는 유의한 상관이 없었으나, K-MMSE 점수 및 교육 정 도와는 유의한 정적상관이 있는 것으로 나타났다. 이러한 결과는 앞서 언급한 과제에 의한 차이 및 교육 정도의 영향으로 설명될 수 있다. 우선, 대화 과제 수행의 경우 연령, 교육 정도 및 선별적인 인 지기능과 유의한 상관이 없는 것으로 나타났다. 대화 과제는 다른 담화 과제에 비해 상대적으로 덜 구조화되어 있고, 담화 산출 시 사 전 계획을 요구하지 않는다(Nippold et al., 2005). 따라서 대화 과제 의 수행은 인지기능에 장애가 없는 일반 노인의 연령이나 교육 정 도와 같은 개인적인 요인이나 정상적인 노화에 따른 인지기능의 저 하 정도의 미세한 수준의 변화에는 영향을 받지 않음을 알 수 있다. 이에 반해, 그림설명 과제의 경우 교육 정도 및 K-MMSE 점수와 유 의한 정적상관을 보였는데, 교육 정도가 높고, 선별적인 수준의 인 지기능이 높을수록 그림의 내용에 적절하고 효율적인 정보를 전달 하는 능력이 뛰어나다는 것은 관련 연구 대부분이 같은 결과를 보고 하고 있다(Ardila \& Rosselli, 1996; Cheon, 2011; Kwon et al., 1998; Mackenzie, 1999). 본 연구의 결과로 그림설명 과제의 수행은 연령, 성별에 비해 교육 정도 및 인지기능의 영향이 크다는 것을 확인할 수 있었으며, 이러한 결과는 노화로 인한 정보 전달 능력의 변화를 민감하게 평가하기 위해서는 대화에 비해 그림설명 과제가 더 유용 함을 시사한다.

셋째, 각 인지기능 수행력과 담화 과제에 따른 CIU 비율의 상관 분석 결과 대화 과제에서의 $\mathrm{CIU}$ 비율은 모든 인지기능 영역의 과 제 수행력과 유의한 상관이 나타나지 않았지만, 그림설명 과제에서 의 CIU 비율은 K-BNT, K-COWAT의 의미, 음소 유창성 점수합과 는 정적상관을 보였으며, K-TMT-e의 Part B의 수행시간 및 오류 수 와는 유의한 부적상관을 보였다. 이러한 결과는 대화 과제의 경우 일반 노인의 인지기능에 큰 영향을 받지 않는 반면, 그림설명 과제 의 수행력은 이름대기 능력, 전두엽 집행기능, 특히 그중에서도 구 어 유창성 및 계획, 과제 전환 능력 등과 관련이 높음을 시사한다. 우선 대화에 비해 그림설명 과제는 제시된 그림에 대한 이해와 함 께 관련 참조물에 대한 적절한 설명 능력을 요구하기 때문에 자연 스러운 상황에서 이루어지는 대화 과제보다 인지적으로 더 많은 부 담을 가지게 되어 과제에 의한 차이가 두드러지게 나타남을 알 수 있다(Bracy \& Drummond, 1993; Cheon, 2011; Choi, 2007).
다음으로 그림설명 과제의 CIU 비율과 K-BNT 점수와의 상관을 설명하기 위해서는 노화로 인한 어휘 인출(lexical retrieval) 능력의 저하(Connor, Spiro, Obler, \& Albert, 2004; Verhaeghen, 2003)와 관련지어 생각해볼 수 있다. 노화와 어휘 산출 능력의 관련성을 설 명한 Connor 등(2004)의 연구에 따르면 일반 노인의 경우 Boston Naming Test의 수행이 10 년에 약 $2 \%$ 씩 저하된다고 보고하였다. 따 라서 본 연구의 결과로 적절한 어휘 인출 능력이 상대적으로 우수 한 노인의 경우 그림설명 과제에서 정확한 어휘를 사용하여 적절한 정보를 전달하는 능력이 뛰어남을 알 수 있다. 이러한 이름대기 능 력 역시 노화로 인한 인지기능의 저하로 설명되는데, 노화로 인한 일반적인 정보처리 속도의 저하(Thornton \& Light, 2006), 집행기 능 중 억제기능의 저하(Zacks \& Hasher, 1997), 기억 능력의 저하 (MacKay \& James, 2004) 등이 관련이 있는 것으로 알려져 있다.

다음으로 담화 산출 능력과 전두엽 집행기능과의 관련성은 기존 의 연구에서 일반 노인의 연구(Arbuckle \& Gold, 1993; Burke, 1997; Gold et al., 1993; Gold \& Arbuckle, 1995) 및 뇌손상 환자들의 연구 들(Coelho, 2002; Tucker \& Hanlon, 1998)에서 보고되고 있다. 본 연구에서는 전두엽 집행기능 검사 중 통제 단어 연상 검사와 기호 잇기 검사의 Part B에서 유의한 상관을 보였다. 전두엽 집행기능은 추상적 개념 형성 능력, 작업기억 능력, 부적절한 반응의 선택적 억 제 능력 및 사회적 행동 조절 능력을 포함한 복잡한 상위 인지기능 이다(Stuss \& Benson, 1986). 이러한 전두엽 집행기능을 평가하기 위한 평가도구 중 본 연구에서 담화의 조직화 능력이나 효율적인 정보 전달 능력을 평가하는 $\mathrm{CIU}$ 비율과 상관을 보인 통제 단어 연 상 및 기호 잇기 검사 Part B의 경우 단일 집행기능이 아닌 보다 복 잡한 상위의 인지기능을 평가하는 것으로 알려져 있다. 우선 통제 단어 연상 검사는 집행기능 중 구어 유창성을 평가하는 검사로 알 려져 있지만 그 밖에도 의미기억(semantic memory) 능력을 평가하 는 중요한 검사이다(Albert, Moss, Tanzi, \& Jones, 2001). 또한, 제한 된 시간 안에 주어진 범주의 어휘들을 산출하기 위한 주의집중력, 모니터링 능력, 작업 기억, 시각적 이미지 재생 능력을 포함한 다양 한 인지기능을 요구하는 복잡한 과제로 알려져 있다(Chertkow \& Bub, 1990). 두 가지 과제를 번갈아 가며 처리해야 하는 기호 잇기 검사 Part B 역시 교번(alternation) 능력, 유연성(flexibility), 억제 (inhibition) 능력, 작업기억, 심적 추적(mental tracking) 및 선택적 주의력 등을 포함한 다양한 인지기능을 요구하는 검사이다(Sanchez-Cubillo et al., 2009). 따라서 이러한 다양한 인지기능을 요구 하는 전두엽 집행기능 검사의 경우 노화로 인한 인지기능 저하를 민감하게 검출하고, 또한 일반 노인의 정보 전달 능력의 저하와의 관련성을 잘 반영하는 것으로 여겨진다. 
그러나 본 연구의 결과 중 SVLT로 평가한 기억력 및 숫자 외우기 검사로 평가한 작업기억 능력을 포함한 주의집중력은 CIU 비율과 유의한 상관을 보이지 않은 것은 기존의 일부 연구 결과와는 일치 하지 않는다. 기존의 연구에서는 일반 노인의 담화 내용의 명제적 적절성 및 조직화 능력은 단기기억 및 작업기억과 유의한 상관을 보 인다고 하였으며(Arbuckle \& Gold, 1993; Kemper et al., 2001), 경도 인지장애(mild cognitive impairment) 환자를 대상으로 한 연구에 서는 담화산출 능력은 작업기억과 관련이 있음을 보고하였다(Caspari \& Parkinson, 2000). 이렇듯 기존의 일부 연구들과 본 연구의 결과가 일치하지 않는 이유로는 첫째, 위의 연구들은 절차 담화(procedural discourse)나 이야기 다시 말하기(story retelling)와 같이 기 억력에 보다 의존해야 하는 과제를 사용하였다는 점(Arbuckle \& Gold, 1993; Caspari \& Parkinson, 2000), 둘째, 노화로 인한 기억력 및 담화 산출 능력의 결과가 종단연구의 결과라는 점(Kemper et al., 2001), 셋째, 경도인지장애로 인한 기억력의 저하를 보이는 환자 들을 대상으로 한 연구라는 점(Caspari \& Parkinson, 2000) 등을 들 수 있다. 이러한 결과는 담화 산출 능력과 기억력과의 관련성은 과제의 종류 및 자극의 복잡성, 인지기능 저하 유무 등의 변수를 고 려하여 보다 면밀히 검토할 필요가 있음을 시사한다(Arbuckle \& Gold, 1993).

마지막으로 그림설명 과제에서 일반 노인의 정보 전달 능력에 교 육정도 및 인지기능 검사의 수행이 미치는 영향을 알아보기 위하 여 중다회귀분석을 실시 한 결과, 본 연구의 인지기능 검사의 결과 가 담화 산출에서의 정보 전달 능력을 유의하게 예측하는 것으로 나타났다.

본 연구는 일반 노인의 실제적인 담화 산출 능력과 인지기능 사 이의 관련성에 관한 연구가 거의 없는 상황에서 대화와 그림설명 과제를 사용하여 평가한 정보 전달 능력과 이름대기, 주의집중력, 기억력, 전두엽 집행기능 등 다양한 인지기능과의 관련성을 알아보 았다는 점에서 의의를 가진다. 그러나 이름대기 능력을 제외한 다 른 인지기능 평가 결과의 경우 통계적으로 유의하더라도 .2-.4 정도 의 다소 낮은 상관계수를 나타내었다. 이러한 결과는 정보 전달 능 력의 경우 인지기능 이외의 다양한 능력이 통합적으로 요구되므로 개별적인 인지기능 검사 결과가 미치는 영향은 상대적으로 작은 것 으로 해석할 수 있다. 또한, 본 연구에서는 CIU비율을 통한 정보 전 달 능력 이외의 다양한 담화 산출 변인과 인지기능과의 관련성을 면밀하게 살펴보지 못한 것이 아쉬움으로 남는다. 앞으로는 다양 한 담화 산출 과제 및 변인을 이용한 담화 산출 능력과 인지기능과 의 관계를 밝히는 후속연구가 진행되기를 기대한다.

\section{REFERENCES}

Albert, M. L., \& Knoefel, J. E. (2011). Clinical neurology of aging (3rd ed.). New York, NY: Oxford University Press.

Albert, M. S. (1994). Age-related changes in cognitive function. In M. S. Albert \& J. E. Knoefel (Eds.), Clinical neurology of aging (2nd ed., pp. 314-328). Oxford, UK: Oxford University Press.

Albert, M. S., Moss, M. B., Tanzi, R., \& Jones, K. (2001). Preclinical prediction of $\mathrm{AD}$ using neuropsychological tests. Journal of the International Neuropsychological Society, 7, 631-639.

Arbuckle, T. Y., \& Gold, D. P. (1993). Aging, inhibition, and verbosity. Journal of Gerontology, 48, 225-232.

Ardila, A., \& Rosselli, M. (1996). Spontaneous language production and aging: sex and educational effects. International Journal of Neuroscience, 87, 71-78.

Blake, M. L. (2006). Clinical relevance of discourse characteristics after right hemisphere brain damage. American Journal of Speech-Language Pathology, 15, 255-267.

Bracy, C. B., \& Drummond, S. S. (1993). Word retrieval in fluent and nonfluent dysphasia: utilization of pictogram. Journal of Communication Disorders, 26, 113-128.

Braver, T. S., Satpute, A. B., Rush, B. K., Racine, C. A., \& Barch, D. M. (2005). Context processing and context maintenance in healthy aging and early stage dementia of the Alzheimer's type. Psychology and Aging, 20, 33-46.

Brookshire, R. H. (2007). Introduction to neurogenic communication disorders (7th ed.). St. Louis, MO: Mosby.

Brookshire, R. H., \& Nicholas, L. E. (1994). Speech sample size and test-retest stability of connected speech measures for adults with aphasia. Journal of Speech, Language, and Hearing Research, 37, 399-407.

Burke, D. M. (1997). Language, aging, and inhibitory deficits: evaluation of a theory. Journals of Gerontology Series B: Psychological Sciences and Social Sciences, 52, 254-264.

Caspari, I., \& Parkinson, S. R. (2000). Effects of memory impairment on discourse. Journal of Neurolinguistics, 13, 15-36.

Cheon, O. (2011). Characteristics of the discourse of elderly in conversation, picture description, and storytelling (Master's thesis). Yonsei University, Seoul, Korea.

Chertkow, H., \& Bub, D. (1990). Semantic memory loss in dementia of Alzheimer's type. Brain, 113, 397-417.

Choi, H. (2012). Discourse characteristics in healthy elderly: effects of aging, 
gender and educational level. Phonetics \& Speech Science, 4, 135-143.

Choi, H. (2013). Characteristics of naming and discourse in patients with amnestic mild cognitive impairment. Journal of Speech-Language \& Hearing Disorders, 22, 17-33.

Choi, Y. H. (2007). Comparison between conversations and picture description utterances of healthy Korean elderly (Master's thesis). Yonsei University, Seoul, Korea.

Coelho, C. A. (2002). Story narratives of adults with closed head injury and non-brain-injured adults: influence of socioeconomic status, elicitation task, and executive functioning. Journal of Speech, Language, and Hearing Research, 45, 1232-1248.

Connor, L. T., Spiro, A., Obler, L. K., \& Albert, M. L. (2004). Change in object naming ability during adulthood. Journals of Gerontology Series B: Psychological Sciences and Social Sciences, 59, 203-209.

Cooper, P. V. (1990). Discourse production and normal aging: performance on oral picture description tasks. Journal of Gerontology, 45, 210-214.

Deloche, G., Jean-Louis, J., \& Seron, X. (1979). Study of the temporal variables in the spontaneous speech of five aphasic patients in two situations, interview and description. Brain and Language, 8, 241-250.

Duong, A., Tardif, A., \& Ska, B. (2003). Discourse about discourse: what is it and how does it progress in Alzheimer's disease? Brain and Cognition, 53, 177-180.

Fleming, V. B., \& Harris, J. L. (2008). Complex discourse production in mild cognitive impairment: detecting subtle changes. Aphasiology, 22, 729-740.

Foos, P. W. (1995). Working memory resource allocation by young, middleaged, and old adults. Experimental Aging Research, 21, 239-250.

Glosser, G., \& Deser, T. (1992). A comparison of changes in macrolinguistic and microlinguistic aspects of discourse production in normal aging. Journal of Gerontology, 47, 266-272.

Gold, D. P., \& Arbuckle, T. Y. (1995). A longitudinal study of off-target verbosity. Journals of Gerontology Series B: Psychological Sciences and Social Sciences, 50, 307-315.

Gold, D. P., Andres, D., Arbuckle, T., \& Zieren, C. (1993). Off-target verbosity and talkativeness in elderly people. Canadian Journal on Aging, 12, 6777.

Goodglass, H., \& Kaplan, E. (1983). The assessment aphasia and related disorders (2nd ed.). Philadelphia, PA: Lea and Febiger.

Hannay, H. J., Howieson, D. B., Loring, D. W., Fischer, J. S., \& Lezak, M. D. (2004). Neuropathology for neuropsychologists. Neuropsychological Assessment, 4, 157-194.
Hasher, L., Zacks, R. T., \& May, C. P. (1999). Inhibitory control, circadian arousal, and age. In D. Gopher \& A. Korat (Eds.), Attention and performance XVII: cognitive regulation of performance, interaction of theory and application (pp. 653-676). Cambridge, MA: MIT Press.

Hinchliffe, F. J., Murdoch, B. E., Chenery, H. J., Baglioni, A. J., \& Harding-Clark, J. (1998). Cognitive-linguistic subgroups in closed-head injury. Brain Inju$r y, 12,369-398$.

Im, E., Kwon, M., \& Sim, H. (2001). The informativeness and efficiency of the connected speech samples in Korean fluent aphasics. Korean Journal of Communication Disorders, 6, 374-391.

Juncos-Rabadán, O., Pereiro, A. X., \& Rodríguez, M. S. (2005). Narrative speech in aging: quantity, information content, and cohesion. Brain and Language, 95, 423-434.

Kang, Y. W. (2006). A normative study of the Korean-Mini Mental State Examination (K-MMSE) in the elderly. Korean Journal of Psychology, 25, 1-12.

Kang, Y. W., \& Na, D. L. (2003). Seoul Verbal Learning Test (SVLT). Seoul: Human Brain Research \& Consulting Co.

Kang, Y., Chin, J., \& Na, D. L. (2002). A normative study of the Digit Span Test for the elderly. Korean Journal of Clinical Psychology, 21, 911-922.

Kang, Y., Chin, J., Na, D. L., Lee, J., \& Park, J. S. (2000). A normative study of the Korean version of Controlled Oral Word Association Test (COWAT) in the elderly. Korean Journal of Clinical Psychology, 19, 385-392.

Kang, Y., Kim, H., \& Na, D. L. (2000). Parallel short forms for the KoreanBoston Naming Test (K-BNT). Journal of the Korean Neurological Association, 18, 144-150.

Kemper, S., Thompson, M., \& Marquis, J. (2001). Longitudinal change in language production: effects of aging and dementia on grammatical complexity and propositional content. Psychology and Aging, 16, 600-614.

Kim, H. H., \& Na, D. L. (1997). Korean version - Boston Naming Test (K-BNT). Seoul: Hakjisa.

Kim, H. H., \& Na, D. L. (2001). Paradise.Korean version-Western Aphasia Battery $(K-W A B)$. Seoul: Paradise Welfare Foundation.

Kliegel, M., Martin, M., McDaniel, M. A., \& Phillips, L. H. (2007). Adult age differences in errand planning: the role of task familiarity and cognitive resources. Experimental Aging Research, 33, 145-161.

Koo, S., \& Choi, H. (2015). Characteristics of spontaneous speech in Broca's aphasic patients through interview and picture description tasks. Journal of Rehabilitation Research, 19, 281-296.

Kwon, M., Kim, H., Choi, S., Na, D. L., \& Lee, K. (1998). A study for analyzing spontaneous speech of Korean adults with CIU scoring system. Korean 
Journal of Communication Disorders, 3, 35-49.

Lee, H. (2006). Development and validation of Korean version of trail making test for elderly persons (Master's thesis). Sungkyunkwan University, Seoul, Korea.

Lee, H., Kim, S., Lee, K. E., Chung, E., \& Park, J. (2012). The age-related changes in cognitive function. Korean Journal of Cognitive \& Biological Psycholo$g y, 24,127-148$.

Lee, J., Kang, Y., \& Na, D. L. (2000). Efficiencies of Stroop inference indexes in healthy older adult and dementia patients. Korean Journal of Clinical Psychology, 19, 807-818.

Lee, Y. M., \& Kim, H. (2001). An utterance analysis of conversations and picture description tasks of Korean adults. Korean Journal of Communication Disorders, 6, 40-52.

MacKay, D. G., \& James, L. E. (2004). Sequencing, speech production, and selective effects of aging on phonological and morphological speech errors. Psychology and Aging, 19, 93-107.

Mackenzie, C. (1999). Adult spoken discourse: the influences of age and education. International Journal of Language \& Communication Disorders, 35 , 269-285.

Madden, D. J., \& Langley, L. K. (2003). Age-related changes in selective attention and perceptual load during visual search. Psychology and Aging, 18, 54-67.

Mar, R. A. (2004). The neuropsychology of narrative: story comprehension, story production and their interrelation. Neuropsychologia, 42, 1414-1434.

Marini, A., Boewe, A., Caltagirone, C., \& Carlomagno, S. (2005). Age-related differences in the production of textual descriptions. Journal of Psycholinguistic Research, 34, 439-463.

Nicholas, L. E., \& Brookshire, R. H. (1993). A system for quantifying the informativeness and efficiency of the connected speech of adults with aphasia. Journal of Speech, Language, and Hearing Research, 36, 338-350.

Nicholas, L. E., \& Brookshire, R. H. (1995). Presence, completeness, and accuracy of main concepts in the connected speech of non-brain-damaged adults and adults with aphasia. Journal of Speech, Language, and Hearing Research, 38, 145-156.

Nippold, M. A., Hesketh, L. J., Duthie, J. K., \& Mansfield, T. C. (2005). Conversational versus expository discourse: a study of syntactic development in children, adolescents, and adults. Journal of Speech, Language, and Hearing Research, 48, 1048-1064.
Park, T. (2004). Cognitive neural mechanisms of aging. Korean Journal of Experimental Psychology, 16, 317-336.

Pushkar, D., Basevitz, P., Arbuckle, T., Nohara-LeClair, M., Lapidus, S., \& Peled, M. (2000). Social behavior and off-target verbosity in elderly people. Psychology and Aging, 15, 361-374.

Ravetti, M. G., Rosso, O. A., Berretta, R., \& Moscato, P. (2010). Uncovering molecular biomarkers that correlate cognitive decline with the changes of hippocampus' gene expression profiles in Alzheimer's disease. PLoS One, 5, e10153.

Sanchez-Cubillo, I., Perianez, J. A., Adrover-Roig, D., Rodriguez-Sanchez, J. M., Rios-Lago, M., Tirapu, J., \& Barcelo, F. (2009). Construct validity of the Trail Making Test: role of task-switching, working memory, inhibition/ interference control, and visuomotor abilities. Journal of the International Neuropsychological Society, 15, 438-450.

Shadden, B. B. (1995). The use of discourse analyses and procedures for communication programming in long-term care facilities. Topics in Language Disorders, 15, 75-86.

Shadden, B., Burnette, R., Eikenberry, B., \& DiBrezzo, R. (1991). All discourse tasks are not created equal. Clinical Aphasiology, 20, 327-342.

Stuss, D. T., \& Benson, D. F. (1986). The frontal lobes. New York, NY: Raven Press.

Thornton, R., \& Light, L. L. (2006). Language comprehension and production in normal aging. In J. E. Birren \& K. W. Schaie (Eds.), Handbook of the psychology of aging (6th ed., pp. 261-287). Burlington, MA: Elsevier Academic Press.

Tucker, F. M., \& Hanlon, R. E. (1998). Effects of mild traumatic brain injury on narrative discourse production. Brain Injury, 12, 783-792.

Ulatowska, H. K., Chapman, S. B., Highley, A. P., \& Prince, J. (1998). Discourse in healthy old-elderly adults: a longitudinal study. Aphasiology, 12, 619-633.

Verhaeghen, P. (2003). Aging and vocabulary score: a meta-analysis. Psychology and Aging, 18, 332-339.

Yorkston, K. M., \& Beukelman, D. R. (1980). An analysis of connected speech samples of aphasic and normal speakers. Journal of Speech \& Hearing Disorders, 45, 27-36.

Zacks, R., \& Hasher, L. (1997). Cognitive gerontology and attentional inhibition: a reply to Burke and McDowd. Journals of Gerontology Series B: Psychological Sciences and Social Sciences, 52, 274-283. 


\section{국문초록}

\section{일반 노인의 정보 전달 능력과 인지기능과의 상관 최현주}

나사렛대학교 언어치료학과

배경 및 목적: 담화 산출 능력은 다양한 인지기능과 관련이 있다. 본 연구는 일반 노인의 담화 산출의 정보 전달 능력을 평가하고, 이러 한 능력에 다양한 인지기능이 미치는 영향을 알아보는 것을 목적으로 하였다. 방법: 본 연구는 일반 노인 60 명(남성 30 명, 여성 30 명)을 대상으로 하였다. 담화 산출 과제는 대화와 그림설명 과제를 사용하였으며, 인지기능으로는 이름대기 능력, 주의집중력, 기억력, 전두엽 집행기능을 평가하였다. 결과: 첫째, Correct Information Unit (CIU) 비율의 성별에 따른 차이는 유의하지 않았지만, 그림설명 과제에 비해 대화 과제에서의 CIU 비율이 유의하게 높았다. 둘째, 대화 과제의 CIU 비율은 연령, 교육 정도, K-MMSE 점수와 유의한 상관이 없 었으나 그림설명 과제의 CIU 비율은 교육 정도 및 K-MMSE 점수와 정적상관을 보였다. 셋째, 대화 과제에서의 CIU 비율은 모든 인지기 능 과제 수행력과 유의한 상관이 없었으나, 그림설명 과제의 CIU 비율은 이름대기, 통제 단어 연상의 의미, 음운 유창성 점수합과는 정 적상관을 보였으며, 기호 잇기 검사 Part B의 수행시간 및 오류 수와는 부적상관을 보였다. 마지막으로 중다회귀분석 결과, 본 연구의 인 지기능 검사의 수행력을 포함한 회귀모형은 유의하게 나타났다. 논의 및 결론: 이와 같은 결과로부터 일반 노인의 그림설명 과제를 통 한 정보 전달 능력은 이름대기 및 전두엽 집행기능과 관련이 있음을 알 수 있다.

핵심어: 담화 산출, 정보 전달, 인지기능, 일반 노인

본 연구는 2013년 정부(교육과학기술부)의 재원으로 한국연구재단의 지원을 받아수행된 연구임(NRF-2013S1A5A8023389).

\section{참고문헌}

강연욱(2006). K-MMSE (Korean-Mini Mental State Examination)의 노인 규준 연구. 한국심리학회지, 25, 1-12.

강연욱, 김향희, 나덕렬(2000). 한국판 보스톤 이름대기 검사(K-BNT)의 병렬 단축형 개발. 대한신경과학회지, 18, 144-150.

강연욱, 나덕렬(2003). 서울언어학습검사(SVLT). 서울: 휴브알엔씨.

강연욱, 진주희, 나덕렬(2002). 숫자 외우기 검사(Digit Span Test)의 노인 규준 연구. 한국심리학회지: 임상, 21, 911-922.

강연욱, 진주희, 나덕렬, 이정희, 박재설(2002). 통제 단어 연상 검사(Controlled Oral Word Association Test)의 노인 규준 연구. 한국심리학회지: 임

상, 19, 385-392.

구서진, 최현주(2015). 대화와 그림설명 과제를 통한 브로카 실어증 환자의 자발화산출 특성. 재활복지, 19, 281-296.

권미선, 김향희, 최상숙, 나덕렬, 이광호(1998). 한국 성인의 자발화 분석에 관한 연구: CIU분석법을 중심으로. 언어청각장애연구, 3, 35-49.

김향희, 나덕렬(1997). 한국판 보스톤 이름대기 검사. 서울: 학지사.

김향희, 나덕렬(2001). 파라다이스·한국판-웨스턴실어증검사. 서울: 파라다이스 복지재단.

박태진(2004). 노화와 인지신경기전. 한국심리학회지: 실험, 16, 317-336.

이영미, 김향희(2001). 대화와 그림설명과제를 통한 한국성인 발화의 비교분석. 언어청각장애연구, 6, 40-52.

이정희, 강연욱, 나덕렬(2000). Stroop 간섭 지표들의 효율성 비교: 정상노인집단과 치매집단을 대상으로. 한국심리학회지: 임상, 19, 807-818.

이한승(2006). 한국판 노인형 기호잇기검사의 개발과 타당도연구. 성균관대학교대학원 석사학위논문.

이혜원, 김선경, 이고은, 정유진, 박지윤(2012). 연령에 따른 인지 변화양상. 한국심리학회지: 인지 및 생물, 24, 127-148.

임은주, 권미선, 심현섭(2001). 경중도에 따른 유창성 실어증환자의 정보전달능력에 관한 연구. 언어청각장애연구, 6, 374-391.

천옥현(2011). 노년층의 담화특성: 대화, 그림 설명, 이야기 말하기의 비교. 연세대학교대학원 석사학위논문.

최윤희(2007). 정상노인의 대화와 그림설명 발화간 특성 비교 분석.연세대학교대학원 석사학위논문.

최현주(2012). 노년층의 담화산출 특성: 노화, 성별, 교육정도에 의한 차이. 말소리와음성과학, 4, 135-143.

최현주(2013). 건망형 경도인지장애 환자의 이름대기 및 담화 과제의 수행 특성. 언어치료연구, 22, 17-33. 